\section{Saúde, ciência e} desenvolvimento: a emergência da leishmaniose tegumentar americana como desafio médico-sanitário no Amazonas

Health, science and development: the emergence of American cutaneous leishmaniasis as a medical and public health challenge in Amazonas state, Brazil

\section{Cláudio de Oliveira Peixoto}

Analista de Gestão em Saúde, Instituto Leônidas e Maria Deane/Fiocruz. Manaus - AM - Brasil

orcid.org/0000-0002-8518-9249

claudio.peixoto@fiocruz.br

Recebido em 11 abr. 2019.

Aprovado em 29 nov. 2019.
PEIXOTO, Claudio de Oliveira. Saúde, ciência e desenvolvimento: a emergência da leishmaniose tegumentar americana como desafio médico-sanitário no Amazonas. História, Ciências, Saúde Manguinhos, Rio de Janeiro, v.27, n.3, jul.-set. 2020, p.741-761.

Resumo

O artigo faz análise histórica da emergência da leishmaniose tegumentar americana como objeto do conhecimento e desafio médicosanitário no Amazonas desde a década de 1970. Fornece visão geral dessa época, as medidas sanitárias e os estudos científicos realizados no contexto de implantação dos principais projetos de desenvolvimento regionais executados em nome da política de integração nacional do governo federal. Utiliza como metodologia a análise documental de leis, produção científica, relatórios de pesquisa, boletins epidemiológicos e jornais. Os resultados da pesquisa mostram que a doença surgiu no Amazonas associando o grande problema de saúde com mudanças políticoeconômicas e alterações socioambientais.

Palavras-chave: leishmaniose tegumentar americana; história das leishmanioses; leishmanioses; políticas públicas de saúde; projetos de desenvolvimento.

\section{Abstract}

The history of the emergence of American cutaneous leishmaniasis in the Brazilian state of Amazonas since the 1970s is analyzed as an object of knowledge and a medical and public health challenge. An overview of the period is provided, including the public health measures and scientific studies undertaken in the context of the execution of large-scale regional developments pursued in the name of national integration by the federal government. The methodology uses documental analysis of laws, the scientific literature, research reports, epidemiological bulletins, and newspapers. The results show that American cutaneous leishmaniasis emerged as a major health problem in Amazonas in close association with the political, economic, and socioenvironmental changes seen in the period.

Keywords: American cutaneous leishmaniasis; history of leishmaniasis; leishmaniasis; public health policies; development projects. 
E m julho de 1985, o menino E.C.B., de 4 anos de idade, morador da Colônia Santo Antônio, saiu de casa para viver uma jornada de dor. Ele foi submetido a mais uma dolorosa injeção, depois das duzentas que já recebera, para tratar as úlceras em seu corpo. Seus pais, Raimundo e Edmilza, contraíram a mesma doença meses antes e acompanharam o filho na "procissão" diária de cerca de meia hora, sob sol ou chuva, até um ambulatório na Cidade Nova, em Manaus. Era um longo caminho com cerca de seis quilômetros.

No seu casebre moravam mais oito crianças e quatro adultos. Nas vizinhanças, praticamente toda casa tinha alguém doente. Essas famílias, que vieram do interior do estado ou de outras plagas em busca de emprego no comércio, na indústria da Zona Franca, no setor de serviços ou no mercado informal de trabalho em Manaus, encontraram uma dura realidade: fome, escassez de moradias e doenças.

A localidade em que viveram surgira de um loteamento sem água encanada, energia elétrica, rede de esgotos e coleta de lixo, sendo ocupado por mais de setecentas famílias. Os moradores da Colônia Santo Antônio recorriam às cacimbas ou ao igarapé, distante cerca de dois quilômetros, para se abastecer de água (relativamente) potável, usada para beber, lavar roupas e realizar a higiene pessoal.

A falta de recursos levava muitos moradores a se aventurar nas matas próximas a fim de caçar pequenos roedores para sua alimentação. Ao fazer isso, conheciam o risco de ser picados pela "tatuquira", apelido dos flebotomíneos, minúsculas moscas transmissoras da doença que grassava na Colônia Santo Antônio.

Foi assim com Paulo e Maria da Conceição. Em sua família, adoeceram todos. A filha, de apenas 1 ano e 4 meses, já tomara mais de trinta doses do medicamento em injeções dolorosas. Nem ela nem os adultos conseguiram se ver livres da doença. Era comum passarem mal por causa dos efeitos colaterais mais ou menos graves da substância injetada. Os antigos utilizavam remédios caseiros feitos à base de ervas e plantas. Eles tiravam o extrato da "batata de onça", planta medicinal comum na região, faziam uma pasta e aplicavam-na sobre as feridas ou acendiam pólvora sobre a pele lesionada, na vã tentativa de "queimar" a doença.

Muitos moradores se lembravam da ex-vizinha Sandra, cujos oito filhos, incluído o de 6 meses, ficaram irreconhecíveis, pois a doença espalhou-se pelo corpo inteiro deles. Geralmente, ela apresentava-se sob a forma de uma ou mais feridas arredondadas que não cicatrizavam. Em alguns casos, irrompiam nódulos ou placas ulcerativas infiltradas, com secreção abundante e fétida, disseminadas pelos membros ou na face. Em outros casos, atingia as mucosas e, gradualmente, destruía os tecidos internos da boca e do nariz.

Enquanto as pessoas enfrentavam a doença, um médico na televisão anunciava para o Brasil o estado de calamidade pública em que se achava Manaus. No pequeno ambulatório da Cidade Nova, outros médicos atendiam os doentes e tentavam controlar a epidemia. No Instituto de Medicina Tropical, na Universidade do Amazonas e no Instituto Nacional de Pesquisas da Amazônia eram investigados os vetores e parasitos responsáveis pela proliferação daqueles casos, realizavam-se experiências com novas drogas para tratá-los e discutiam-se medidas para minimizar os efeitos da epidemia.

Alheios ao mundo dos estudos médico-científicos epidemiológicos e mesmo às instruções distribuídas pela Secretaria de Saúde, as pessoas como Paulo, Maria da Conceição e Sandra não sabiam que a leishmaniose era uma doença causada por um 
protozoário do gênero Leishmania. Mas os médicos que iam a campo procuravam convencê-las a não andar nas matas e igarapés de manhã cedo ou ao entardecer, porque era nessas horas que o mosquito transmissor saía para se alimentar. Mas como deixariam de ir ao igarapé, se não havia água encanada? Como não entrariam na mata, se a floresta era o quintal de casa? As pessoas não conseguiam entender por que aquela doença se tornara um problema de saúde tão grande.

Essa narrativa baseia-se em informações de artigos científicos e notícias de jornais publicadas em meados dos anos 1980 (Surto..., 12 jul. 1985; Leishmaniose..., 14 jul. 1985).

A partir da década de 1970, o Amazonas tornou-se uma região importante para o estudo das leishmanioses. Cientistas buscavam identificar a biologia e a distribuição de diferentes espécies de Leishmania, seus ciclos em animais silvestres que servem como hospedeiros reservatórios, nos insetos vetores e no hospedeiro humano. Estavam também atentos às sinergias entre vetores, parasitos e os impactos socioambientais decorrentes de processos de ocupação do território amazônico.

A leishmaniose tegumentar americana (LTA) foi reconhecida como problema de saúde na Amazônia no começo do século XX (Jogas Jr., 2014, p.19), mas foi nos anos 1970 que se tornou questão grave e disseminada e adquiriu crescente importância no meio científico local, nacional e internacional. A Organização Mundial de Saúde (OMS) a identifica nos dias atuais como uma das doenças tropicais mais negligenciadas do mundo, pois afeta a saúde e a vida da população pobre dos países em desenvolvimento e, normalmente, não recebe muita atenção das autoridades nem fundos adequados para pesquisa (Conceição-Silva, Alves, 2014, p.17).

Surtos e epidemias irromperam no Amazonas em consequência do crescimento urbano e demográfico de Manaus e da implantação de projetos de desenvolvimento que tiveram grande impacto socioambiental. A LTA passou então a figurar, junto com a malária, entre as endemias de grande magnitude no Amazonas, atraindo a atenção de investigadores nativos e estrangeiros com formação em medicina e biologia, que passaram a desenvolver pesquisas em instituições locais associadas de forma cada vez mais estreita a instituições de outras partes do Brasil e do mundo.

Essa dinâmica resultou em volume considerável de estudos sobre a epidemiologia e a patogenia das leishmanioses cutânea e mucocutânea, sobre a taxonomia e a biologia das espécies de protozoários que causam a doença, espécies de insetos flebotomíneos que atuam como vetores e de animais que hospedam leishmânias. Tais estudos ajudaram a projetar nacional e internacionalmente a região amazônica no âmbito da medicina tropical, mas não tiveram desdobramentos de igual magnitude no campo da saúde pública, pois se traduziram em poucas práticas proveitosas no que tange à prevenção e ao controle da doença (OMS, 2010, p.XII).

Estudos recentes mostram que as mudanças no perfil da LTA estão relacionadas aos processos de urbanização e industrialização no Amazonas. No começo do século XX, durante a época da borracha, ela teve perfil predominantemente silvestre e afetou principalmente trabalhadores que adentravam a floresta. A partir da década de 1970, surtos e epidemias irromperam entre a população de áreas urbanas e periurbanas de Manaus e outras cidades, deixando de ser uma doença apenas silvestre. O Amazonas transformou-se, então, numa das regiões mais endêmicas do Brasil e do mundo (Guerra et al., 2015, p.13). 
Neste artigo, faço uma análise da emergência da LTA como desafio médico-sanitário no contexto de implantação dos projetos de desenvolvimento no Amazonas. Relaciono os dados epidemiológicos com a construção das rodovias Manaus-Itacoatiara - AM-010 (1965) e Manaus-Boa Vista - BR-174 (1978), a exploração mineral em Pitinga (1982), a construção da Hidrelétrica de Balbina (1988), do gasoduto Coari-Manaus (2006) e a criação da Zona Franca de Manaus (1957). Considero relevantes os estudos sobre as leishmanioses, principalmente aqueles desenvolvidos na Clínica de Moléstias Tropicais fundada em 1970, que deu origem à Fundação de Medicina Tropical Heitor Vieira Dourado (FMT-HDV), e no Instituto Nacional de Pesquisas da Amazônia (Inpa), em particular, o Laboratório de Leishmaniose e Doença de Chagas, criado em 1975. Os cientistas destas duas instituições se destacaram na produção de conhecimentos sobre a LTA e outras doenças na região.

\section{Os projetos de desenvolvimento e a LTA no Amazonas}

Uma vasta literatura no campo da medicina tropical tem relacionado as alterações no perfil de transmissão da LTA às mudanças econômicas e socioambientais no Brasil. Vale e Furtado (2005, p.424) apontam que ela se disseminou praticamente por todo o território brasileiro a partir da década de 1950. Nesse contexto, aumentaram as migrações das zonas rurais para as grandes cidades, e foi impulsionada a urbanização nas regiões Sudeste e Nordeste pela construção de estradas e rodovias.

Tanto as leishmanioses tegumentares como as viscerais irromperam de forma epidêmica em vários pontos do Nordeste no começo dos anos 1950; ali foram realizados inquéritos epidemiológicos combinados ao uso do DDT e de outros inseticidas de ação residual contra os flebotomíneos. Tais ações, na esteira das campanhas contra a malária, levaram ao declínio das duas formas da enfermidade. Mas, depois, elas voltaram a crescer e a se expandir geograficamente pelo país (Vale, Furtado, 2005, p. 424).

A conjuntura econômica do final da década de 1960 e início dos anos 1970 favoreceu os investimentos na região amazônica. Os projetos de desenvolvimento do governo civilmilitar, sob o lema "integrar para não entregar", tinham em vista a recuperação econômica regional, a manutenção das fronteiras, a diminuição dos conflitos pela posse de terras em outras regiões do país, a ocupação do espaço amazônico, visto como "vazio demográfico", e a "superação das tensões que punham em jogo algumas das condições de manutenção e expansão da acumulação capitalista no Brasil" (Seráfico, Seráfico, 2005, p.103).

$\mathrm{O}$ aumento dos casos de doenças infecciosas na região ocorreu no contexto de um grande fluxo populacional estimulado pelo governo federal com a construção das rodovias BelémBrasília (1958) e Transamazônica (1970), entre outras. O desmatamento, fator ecológico que caracterizou essa política de imigração dirigida, influenciou, principalmente, o aumento da malária (Andrade, 2016, p.75). Marco importante foi a Zona Franca de Manaus (ZFM), ${ }^{1}$ projeto concebido em 1957 e implantado a partir de 1967. A atração exercida pelo parque comercial e industrial causou migração de pessoas de outros estados e de municípios do interior para Manaus em busca de emprego e melhores condições de vida (Schweickardt, Martins, 2017, p.28). 
Além desse grande fluxo populacional, os surtos de malária e LTA no Amazonas foram atribuídos à expansão de áreas agrícolas, exploração mineral e petrolífera, construção de estradas, hidrelétricas e a ocupação de novas áreas urbanas a partir da década de 1970 (Guerra et al., 2015, p.13). Esses empreendimentos intensificaram o processo migratório e desencadearam uma série de mudanças no ambiente, fazendo com que os desmatamentos gerassem sérios agravos à saúde, perdas ecológicas de grandes dimensões e alterações climáticas sensíveis (Patz et al., 2000, p.1396; Paes, Barros, Toledo, 1997, p.II.3.7).

De acordo com Araújo Filho (1981, p.187), os desmatamentos redundam na migração de reservatórios naturais de Leishmania, como marsupiais, edentados e roedores, para outras áreas, forçando os flebotomíneos a realizar seus repastos sanguíneos no homem. Estudos nos últimos trinta anos mostram que algumas espécies de flebótomos adaptaramse a ambientes periurbanos em consequência das alterações socioambientais (Brasil, 2017, p.9).

Os impactos sobre as relações entre insetos vetores, parasitas, hospedeiros humanos e outros reservatórios (silvestres e domésticos) resultaram em aumento do número de casos, de surtos localizados e até mesmo de fortes epidemias da doença (Barrett, Senra, 1989, p.256). A intensificação dos fluxos imigratório e emigratório, por sua vez, contribuiu para a dispersão da LTA para áreas indenes (Sousa, Pearson, 2009, p.916; Altamirano-Enciso et al., 2003, p.858).

Estudos sobre essa dinâmica, a partir de então, demonstraram que ela está diretamente ligada às mudanças provocadas pelos projetos de desenvolvimento regional. O Quadro 1 mostra grandes projetos que interferiram nos processos de urbanização, industrialização e na epidemiologia da LTA no Amazonas.

Quadro 1 - Principais empreendimentos no estado do Amazonas importantes para o mapeamento da LTA (1960- 2015)

\begin{tabular}{|c|l|}
\hline Período & \multicolumn{1}{|c|}{ Empreendimento } \\
\hline $1960-1970$ & Expansão da fronteira agrícola do Centro-oeste para o sul do estado do Amazonas \\
\hline $1970-1980$ & $\begin{array}{l}\text { Construção da infraestrutura rodoviária do Amazonas: Manaus-Itacoatiara (AM-010) Manaus- } \\
\text { BoaVista (BR-174); Manaus Porto Velho (BR-319); Transamazônica (BR-320) }\end{array}$ \\
\hline 1967 & Implantação da Zona Franca de Manaus \\
\hline 1978 & Exploração de minério em Pitinga \\
\hline 2006 & Construção da Hidrelétrica de Balbina \\
\hline 2006 & Construção do Gasoduto Coari-Manaus \\
\hline 2006 & Descoberta de novas áreas de mineração nos municípios de Novo Aripuanã, Apuí e Humaitá \\
\hline $1970-2015$ & Construção de conjuntos habitacionais/ocupações de terra em Manaus \\
\hline
\end{tabular}

Fonte: Peixoto (2017). 
Tais empreendimentos e projetos de desenvolvimento, embora implementados por governos de diferentes colorações políticas, tiveram características comuns: foram e continuam a ser excludentes e predatórios das diversidades socioculturais e ambientais da Amazônia brasileira. Além disso, um novo modo de ocupação trouxe consigo o rastro de doenças infecciosas que afetaram as condições de vida e de saúde da população no território amazônico.

\section{Dos rios às rodovias: os caminhos da leishmaniose}

No começo do século XX, irromperam no estado de São Paulo epidemias de úlceras cutâneas e mucosas durante a construção de seu sistema ferroviário. Lá se identificou, em 1909, pela primeira vez no país, o agente etiológico da leishmaniose nos canteiros de obras da Estrada de Ferro Noroeste do Brasil, que interligaria São Paulo e Mato Grosso (Pessoa, Barreto, 1944, p.31). A construção de ferrovias no Brasil tinha como objetivo a integração do território nacional, o alargamento do mercado interno e do escoamento de produtos agrícolas e minerais para exportação. Doenças tropicais como leishmaniose e malária tiveram forte impacto nessas e em outras obras de infraestrutura. Associadas à modernização republicana e a novas sinergias entre processos biológicos e socioeconômicos, foram objeto de ações sanitárias relativamente bem-sucedidas e induziram importantes investigações no campo da medicina tropical (Benchimol, Silva, 2008, p.720).

No Amazonas, ainda no início do século XX, as informações sobre a leishmaniose (denominada regionalmente "feridas bravas") diziam respeito sobretudo a pacientes levados de zonas interioranas e de longínquos seringais e povoados para as capitais, Belém, Manaus e Iquitos. As localidades de onde provinham os doentes eram quase impermeáveis a ações do Estado e raramente acessíveis a observações feitas por viajantes e letrados. Entretanto, nas décadas de 1960 e 1970, a incidência da leishmaniose na Amazônia aumentou substancialmente, fato relacionado à construção de rodovias com o objetivo de integrar o território amazônico ao restante do país, assegurar o escoamento de produtos naturais e a exportação de produtos da Zona Franca de Manaus para outros mercados.

Diferentemente de outras regiões, na Amazônia são os rios as principais vias de transporte e comunicação; e, portanto, agentes relevantes para a compreensão dos processos de saúde e doença, tanto por sua importância socioeconômica e política quanto biológica, isto é, a ação que exercem sobre os ciclos de vida de patógenos, hospedeiros e vetores. Os rios Amazonas, Juruá, Purus, Madeira, Negro, seus afluentes e toda a rede hidrográfica formada por igarapés, furos e paranás influenciaram e seguem influenciando não só a história política, social e econômica da Amazônia, como também, em maior ou menor medida, o curso de doenças infecciosas.

De acordo com Gonçalves (2008, p.79), a configuração histórico-geográfica e social da região amazônica obedeceu, grosso modo, a dois padrões. O padrão rio-várzea-floresta predominou até pouco além de meados do século XX. Era caraterizado pela organização a partir dos rios - ponto de referência da vida sociocultural, do modo de vida e da identidade das populações ribeirinhas e indígenas - e pelo extrativismo florestal, a economia baseada na exploração de produtos da floresta, como a borracha. 
O segundo padrão - rodovia-terra firme-subsolo - está ligado ao modelo de desenvolvimento econômico instaurado por volta da década de 1970, quando a Amazônia se tornou área de interesse estratégico para o Estado nacional, adotando políticas e medidas visando à "incorporação de fronteiras territoriais, científicas e culturais" (Faulhaber, 2005, p.241).

Instaurou-se, então, um novo modo de ocupação da região, caracterizado pela construção de estradas e rodovias, pela industrialização e pela exploração mineral. Esse padrão começou a ser construído com a política desenvolvimentista do governo Juscelino Kubitschek e a construção da rodovia Belém-Brasília, na década de 1950, e daquelas que foram construídas nos governos subsequentes (Gonçalves, 2008, p.79).

No rastro da construção das rodovias houve uma vigorosa expansão da fronteira agrícola e pecuária da região Centro-oeste para a sul do Amazonas a partir da década de 1960, que resultou em fortes impactos ambientais nos municípios de Lábrea, Novo Aripuanã, Humaitá, Boca do Acre e Apuí. A implantação de projetos de colonização agrícola e a exploração do ouro nos garimpos foi outro processo caracterizado por ocupação desordenada, exploração predatória do solo e subsolo, e que levou a grandes áreas desmatadas e graves surtos de leishmaniose (Guerra et al., 2015, p.15).

A migração e as políticas de desenvolvimento executadas no Amazonas, a partir de então, mudaram o padrão de ocupação do território, mas isso não significou o abandono da referência aos rios. Sua influência persiste, mas associada às novas atividades que advieram da construção das estradas e rodovias, como a exploração econômica da terra e a implantação de assentamentos humanos ao longo de seu percurso, que influenciaram os surtos de leishmaniose e outras doenças.

Nesse período, o Inpa e a Clínica de Moléstias Tropicais desenvolveram importantes investigações entomológicas, biológicas, médicas e epidemiológicas nas áreas modificadas pelos empreendimentos acima mencionados. Djalma da Cunha Batista, ${ }^{2}$ que dirigiu o Inpa de 1959 a 1968, atribuiu o aumento do número de vítimas da LTA à colonização ao longo das estradas recém-construídas e à perturbação do habitat dos mosquitos transmissores, ou seja, à destruição do seu ciclo ecológico (Batista, 2007).

É importante destacar que, até 1968, segundo a imprensa, as estatísticas da Organização Mundial de Saúde (OMS) para os casos de leishmaniose cutânea na Amazônia eram ínfimas; somavam cerca de 71 desde a década de 1940 até aquele ano. Entretanto, os estudos dos médicos Mário Augusto Pinto de Moraes (1926-2016) ${ }^{3}$ no Amazonas e Domingos Barbosa Silva (1917-1996), dermatologista do Departamento de Patologia da Universidade Federal do Pará, apontaram a existência de cerca de 633 casos da doença entre 1954 e 1968. Outros 266 casos foram registrados pela seção de parasitologia do Instituto Evandro Chagas (IEC) no Pará (Fonseca, 19 jun. 1977, p.1). A doença afligia, enfim, uma população bem maior que a estimada pela OMS, mas ainda não se conheciam bem as espécies de parasitos e os vetores responsáveis pela sua ocorrência na região.

$\mathrm{Na}$ época do apogeu da borracha, a leishmaniose e outras doenças parasitárias apresentavam-se, principalmente, ao longo dos principais rios e seus afluentes. Com o novo padrão de ocupação territorial, além dos rios, novos caminhos foram traçados aos humanos e suas doenças pelas estradas e seus ramais. As principais instituições de pesquisa da região estabeleceram o desafio de percorrer esses caminhos para estudar a ecologia dos vetores 
e a epidemiologia das principais doenças. Coletaram dados, insetos, parasitas e animais vertebrados, realizaram atendimentos clínicos, experimentos e levantamentos do impacto das mudanças ambientais e seus efeitos sobre a saúde e a biodiversidade.

\section{Rodovias, saúde e ciência: desvendando a ecologia dos vetores e a epidemiologia da LTA no Amazonas}

Duas rodovias se destacaram na epidemiologia dos casos de leishmaniose tegumentar ao longo de seu trajeto. A Manaus-Itacoatiara - AM-010 (na época AM-1) - foi a primeira rodovia do Amazonas. Suas obras começaram em 1955, no governo de Plínio Ramos Coelho (1955-1959). Foi inaugurada dez anos depois, em 1965, no governo de Arthur Cézar Ferreira Reis. ${ }^{4}$ Ao longo de seu sinuoso percurso de 269 quilômetros floresta adentro, a rodovia corta uma região riquíssima em madeiras e biodiversidade, com inúmeros rios e igarapés. A doença grassou nos diversos assentamentos agrários lá implantados e entre os militares que utilizavam esse território para treinamento (Guerra et al., 2003, p.588).

A Manaus-Boa Vista - BR-174 fez parte do Plano Rodoviário Nacional do governo Juscelino Kubistchek (1956-1961) e, finalmente, foi inaugurada em 1978. Construída para ser uma via atrelada à exploração de minério em terras indígenas e escoar produtos naturais como castanha, borracha e pau-rosa, a rodovia tornou-se também rota de exportação de produtos da Zona Franca de Manaus para os mercados do norte, a começar pela Venezuela. Sua construção desalojou e quase dizimou por inteiro a etnia indígena Waimiri-Atroari, que habitava aquelas terras, ao entregar os recursos naturais do solo e subsolo ao capital internacional (Silva Filho, 2015, p.40).

Repetindo a velha tragédia da colonização europeia, doenças como sarampo, gripe, varíola, tuberculose e malária aniquilaram aldeias inteiras. Essas patologias foram introduzidas pelos funcionários e trabalhadores recrutados para as obras. Os indígenas foram dizimados também por matadores profissionais e por militares pelo fato de ser considerados obstáculos à livre exploração das riquezas naturais na Amazônia (Rodrigues, 2013, p.239).

No Amazonas e no estado vizinho, o Pará, pesquisadores estrangeiros e brasileiros foram atraídos para o estudo da enorme diversidade da fauna de flebotomíneos e de protozoários do gênero Leishmania na Amazônia. Favorecida pelo clima e pelo ambiente propícios a seu desenvolvimento, a região tornou-se singular para a pesquisa das leishmanioses, uma vez que as alterações antrópicas que estavam acontecendo ao longo das rodovias, sob a forma de ocupações, desmatamentos e outras alterações do ambiente, transformaram essas e outras doenças em grave problema de saúde pública na região.

Já estava em curso no início da década de 1960, na Segunda Divisão de Pesquisas Médicas do Inpa, um programa que visava identificar os reservatórios silvestres de Leishmania braziliensis, o suposto agente da LTA que circulava na região amazônica. Zoólogos e parasitologistas examinavam os mamíferos silvestres, capturados numa estação-piloto criada no km 46 da Manaus-Itacoatiara e realizavam expedições, algumas lideradas por pesquisadores estrangeiros a várias áreas do estado e ao território de Roraima, ao Acre e a Rondônia. Entre as espécies coletadas nessas expedições estavam flebotomíneos, possíveis vetores de Leishmania (Inpa, 1963, p.6). 
Os pesquisadores da Segunda Divisão estavam antenados com o conhecimento sobre a leishmaniose e seus vetores no Brasil e em outros países. Eles dominavam as técnicas de captura com armadilhas de luz, iscas humanas, a dissecação dos vetores, o isolamento dos parasitos, a maceração em solução salina e a infecção experimental. Conheciam as espécies, até então, identificadas nos trabalhos de Pifano ${ }^{5}$ na Venezuela e Floch ${ }^{6}$ na Guiana. Porém, não obtiveram sucesso em encontrar flagelados do ciclo vital da doença nos insetos e animais capturados.

No Instituto Evandro Chagas, no Pará, Ralph Lainson e Jeffrey Jon Shaw, cientistas britânicos, estabeleceram uma unidade de parasitologia financiada pela Welcome Foundation em 1965. O objetivo principal desses cientistas era a identificação (por meio da parasitologia, da entomologia e da zoologia médica) de novas espécies de Leishmania, seus vetores e hospedeiros vertebrados na Amazônia brasileira. Os trabalhos feitos por esses parasitologistas, em colaboração com outros investigadores britânicos e brasileiros, ocasionaram uma reviravolta na forma como a leishmaniose tegumentar era compreendida. Mostraram eles que as populações de parasitos, com seus respectivos vetores e hospedeiros vertebrados, eram muito mais heterogêneas do que se imaginava ${ }^{7}$ (Shaw, 2016, p.37; Lainson, 2010, p.14).

A busca por novas espécies no Amazonas se deu em função dos aumentos dos casos clínicos da doença, inicialmente, ao longo das rodovias recém-construídas. Na altura do km 65 da AM-010, ainda na década de 1960, o governo do estado do Amazonas cedeu ao Exército brasileiro uma área de floresta primária de terra firme entre o rio Puraquequara e o município de Rio Preto da Eva. Lá foi instalada a Base BL1 do Centro de Instrução de Guerra na Selva (Cigs). Essa unidade especializada ocupava a área que passou a ser conhecida como o "Quadrado Maldito", entre outras razões por causa das doenças que infernizavam a vida dos militares desde a implantação da base. Duas décadas depois, um surto de LTA atingiu mais de $80 \%$ do efetivo de soldados que ali realizavam treinamento militar (Pinheiro, Luz, Franco, 2008, p.166).

A maioria dos pacientes de LTA era atendida e estudada em Manaus. O agravamento da situação sanitária nessa cidade, por efeito especialmente de doenças que tradicionalmente constituíam o objeto da medicina tropical, levou à criação de uma pequena Clínica de Moléstias Tropicais, que começou a funcionar precariamente em 1970 no anexo do Hospital Getúlio Vargas, administrado pelo governo do estado por meio da Secretaria de Saúde e Assistência Social (SAS) (Barros, 12 set. 2016).

A iniciativa partiu de Heitor Vieira Dourado (1938-2010) e Carlos Augusto Telles de Borborema (1939-2017), dois professores do Departamento de Ciências da Saúde da Universidade do Amazonas. A eles se juntaram 16 estudantes que cursavam a graduação em medicina. A clínica foi batizada com o nome de "Dr. Luiz Montenegro", transformada em hospital em 1974 e convertida quatro anos depois em Instituto de Medicina Tropical (IMT), atual Fundação de Medicina Tropical Heitor Vieira Dourado (FMT-HVD), instituição reconhecida internacionalmente como referência na pesquisa e no tratamento das leishmanioses e outras doenças infecciosas e parasitárias (Barros, 12 set. 2016).

A Clínica de Moléstias Tropicais foi a concretização de um projeto de caráter a princípio individual, isolado no contexto médico local, de atender à carência de uma instituição de 
pesquisas voltada para as doenças tropicais que afloravam como grande problema de saúde pública no estado. Nessa mesma conjuntura, pesquisadores e instituições biomédicas de outras regiões do país e do exterior voltavam a se interessar por aquela porção dos "trópicos", a Amazônia, atraídos pela "matéria-prima" que por ela oferecia aos estudos em medicina tropical.

As pesquisas desenvolvidas nos primeiros anos de existência da clínica envolveram, de um lado, intensas sinergias entre a ciência e a assistência médico-terapêutica a pacientes da rede pública de saúde. De outro lado, a prática e a formação de seus médicos investigadores entrelaçaram-se aos interesses de pesquisa de pesquisadores e instituições de outras partes do Brasil, e seus médicos e cientistas passaram a investigar, entre outras endemias, a LTA nos canteiros das grandes obras implementadas durante o regime civil-militar na capital e no interior do estado.

No Amazonas, à malária, objeto tradicional de interesse da medicina tropical, juntava-se agora a leishmaniose, endemia de magnitude crescente, e também a filariose, a febre tifoide, as hepatites, as doenças sexualmente transmissíveis, a amebíase e outras verminoses, as arboviroses e depois a Aids. A incidência cada vez maior dessas doenças tornava a pesquisa sobre elas uma necessidade crucial não apenas por razões acadêmicas, mas para subsidiar as políticas de controle e prevenção e a assistência médica às suas vítimas.

A construção de um hospital próprio para as doenças tropicais seria justificada em razão de a Clínica de Moléstias Tropicais não mais suportar o grande afluxo de pessoas que adoeciam nas áreas periurbanas de Manaus ou em localidades e lugarejos distantes do Amazonas. Nesse quadro, sobressai o aumento da transmissão da leishmaniose tegumentar em Manaus. Isso fez recrudescer a necessidade de ampliar a assistência médica e as pesquisas relacionadas às doenças infecciosas e parasitárias às quais, como vimos, já vinha se dedicando o Inpa.

Jorge Ramon Arias (1943-2014), panamenho naturalizado americano, doutor em entomologia médica pela Universidade da Califórnia, chegou ao Amazonas em 1974 para montar o Laboratório de Leishmaniose e Doença de Chagas no Inpa. Arias e o entomólogo amazonense Rui Alves de Freitas iniciaram seus estudos em áreas próximas à rodovia AM010 e nas matas ao redor dos conjuntos Parque 10 de novembro e Parque das Laranjeiras, no município de Manaus. Com a mesma abordagem de Lainson e Shaw, pesquisaram a fauna de flebotomíneos, as espécies de Leishmania e como estas variáveis se traduziam em diferentes formas clínicas da LTA em hospedeiros humanos (Arias, Freitas, 1978, p.387-395).

Os espécimes de flebótomos eram coletados por meio de capturas diretas com isca humana ou armadilhas, tipo CDC, importadas dos EUA. Entre 1977 e 1982, os pesquisadores do laboratório de Arias confirmaram que a espécie Lutzomyia umbratilis era o principal vetor da Leishmania (Viannia) guyanensis, a principal causadora da LTA na região de Manaus, norte do Amazonas e Guianas. Já a Leishmania (Viannia) braziliensis era encontrada no sul do rio Amazonas, e a Leishmania (Leishmania) amazonensis - responsável pela forma difusa (mais rara e agressiva da doença) - foi encontrada tanto no norte quanto no sul do estado. Essa nova classificação teve como base a revisão das espécies neotropicais estudadas no Brasil desde 1965, proposta por Lainson e Shaw em 1987 em substituição à ideia, que prevalecera até a década de 1960, de que todas as formas de LTA se deviam à L. braziliensis (Lainson, 2010, p.14). 
Entre maio de 1976 e abril de 1977, Arias e Freitas, ao encontrar flagelados da Leishmania (Viannia) guyanensis em espécimes de moscas capturadas ao norte do rio Amazonas e não encontrar qualquer infecção nos flebótomos oriundos da região ao sul do rio, levantaram a hipótese de que esse sistema fluvial atuava como barreira natural na distribuição dos ciclos vetor/parasito/homem (Arias, Freitas, 1978, p.387). O conhecimento da distribuição espacial e ecológica dos flebotomíneos estava em pauta por sua importância na vigilância epidemiológica das leishmanioses.

Estudos do Inpa e do IMT identificaram nos núcleos de colonização estabelecidos em áreas adjacentes às rodovias AM-010 e BR-174 várias espécies de flebotomíneos envolvidas na transmissão da LTA: Luztomia anduzei, Luztomia whitmam e Luztomia umbratilis, este, o principal vetor da região e espécie extremamente antropofílica associada à transmissão da Leishmaniose (V.) guyanensis, que, como vimos, ocorre ao norte do rio Amazonas, em áreas de colonização recente (Arias, Freitas, 1978, p.387).

No final da década de 1970, a equipe e a produção científica do laboratório de Arias diversificaram-se com a chegada do casal de pesquisadores Roberto e Maricleide Naiff, discípulos de Lainson e Shaw no Instituto Evandro Chagas, e com a posterior contratação do entomólogo britânico Toby Vincent Barrett. Arias, após 12 anos de trabalho como pesquisador no Inpa, deixou o Amazonas em 1986, a convite da representação da Organização Pan-americana em Saúde (Opas) para atuar em Brasília e, posteriormente, no Panamá, na Venezuela e nos EUA, entregando a chefia do laboratório a Barrett. A chegada de Toby Barrett ao laboratório chefiado por Arias fortaleceu os estudos de identificação e taxonomia das espécies que já eram realizados ali.

No IMT, os médicos que trabalhavam com leishmaniose estavam envolvidos com assistência a pacientes da rede pública. A incidência da doença era crescente nas estatísticas oficiais, mas, até então, poucos trabalhos científicos eram publicados sobre os surtos ou as medidas adotadas para seu controle. Nesse período, a construção de grandes barragens na Amazônia - Tucuruí, no Pará (1985), Balbina, no Amazonas (1988), e Samuel, em Rondônia (1982) -, aliada à industrialização de Manaus, forçou o deslocamento de povos indígenas e outras comunidades tradicionais de suas terras e colocou em risco a biodiversidade da região amazônica, a saúde dos trabalhadores e da população atingida por esses projetos.

\section{Pitinga e Balbina: desenvolvimento, desastre ecológico e leishmaniose}

A década de 1980 foi marcada por outros projetos que visavam "desenvolver" a região, mas que trouxeram profundos impactos socioambientais e proliferação de doenças, como a exploração mineral no distrito de Pitinga (1982) e a construção da Hidrelétrica de Balbina (1988), ambos localizados no trajeto da BR-174, nas terras indígenas dos Waimiri-Atroari.

Em 1979, a 320km de Manaus, foi descoberta a maior mina polimineral do mundo. Lá foi construída, então, Vila Pitinga, sede administrativa e local de moradia dos trabalhadores da mineradora Taboca, empresa do grupo Paranapanema, adquirida em 2008 pela gigante mineradora peruana Minsur. Em 1982, foi iniciada a extração de vários minerais, como o estanho, obtido principalmente da cassiterita, e também ferro, nióbio e tântalo. Os 
trabalhadores contratados logo foram vitimados por surtos de leishmaniose e outras endemias (Rodrigues, 2013, p.170).

O vale do rio Pitinga, como a maior parte do estado, é região de clima tropical quente e úmido, com chuvas frequentes praticamente o ano todo, onde se encontra uma fauna diversificada de mamíferos silvestres e insetos, inclusive flebótomos. O terreno da sede do distrito foi totalmente desmatado para dar lugar à vila, dividida em setores: A, B, C e D. Também foram construídos: igreja, clubes, hotel, área comercial, creche, escola, restaurante, aeroporto e uma hidrelétrica particular com $25 \mathrm{MW}$ de potência, o que aumentou o impacto sobre o ambiente.

Para atender aos casos de doenças entre trabalhadores e residentes, foi levantado um hospital. Ao chegar ao povoado, os investigadores do Inpa e do IMT examinavam as fichas de controle dos pacientes, a começar pelos que apresentavam lesões. Eles eram submetidos a testes para revelar a infecção por Leishmania e, comprovando-se o diagnóstico, encaminhados para tratamento. Os estudos tiveram por objetivo esclarecer a epidemiologia das doenças que grassavam no lugar. No caso da leishmaniose, foram feitas capturas de flebótomos e esforços para localizar seus potenciais criadouros, assim como para avaliar a eficácia das medidas de controle adotadas pela empresa mineradora (Chagas et al., 2006, p.188).

Os casos de LTA registrados em Vila Pitinga envolviam, em sua maioria, homens que trabalhavam em estreito contato com a floresta. As medidas adotadas para o controle da doença consistiram na borrifação de inseticida ao final da tarde ("fumacê"), na proibição da caça de animais silvestres e de banhos ou acampamentos na floresta. Essas medidas, aliadas a ações de educação em saúde, parecem ter levado ao declínio da incidência da doença na região (Chagas et al., 2006, p.191).

Ainda no território Waimiri-Atroari, a construção da Usina Hidrelétrica de Balbina, no rio Uatumã, inaugurada parcialmente em 1988, inundou $2.360 \mathrm{~km}^{2}$ de floresta. Além de causar um dos maiores desastres ambientais do Brasil, esse empreendimento ajudou a desestruturar o modo de vida da etnia e de outras populações que habitavam a região (Rodrigues, 2013, p.80).

A legislação ambiental passou a exigir, desde 1981, a apresentação de Relatórios de Impacto Ambiental (Rima) ${ }^{8}$ para a concessão do licenciamento de construção das hidrelétricas. Essa exigência favoreceu a assinatura de convênios entre o Inpa e a companhia Eletronorte, proporcionando recursos para os estudos científicos sobre a fauna de vetores. Os cientistas identificaram novas espécies de flebótomos e analisaram os efeitos do desmatamento na proliferação dos casos de leishmaniose (Araújo Filho, 1981, p.187).

A Vila de Balbina surgiu para abrigar cerca de quatro mil trabalhadores recrutados para a construção da hidrelétrica e seus dois mil familiares. Era dividida em duas áreas chamadas de Waimiri e Atroari, numa irônica homenagem ao grupo étnico que vinha sendo dizimado. Relatórios de campo mostram que, em 1987, foi celebrado um convênio entre o Ministério da Ciência e Tecnologia, a Eletrobras e o Inpa, visando realizar experimentos com produtos químicos contra os vetores, identificar espécies e mitigar os impactos ambientais decorrentes da inundação do território da represa (Inpa, 23 jan. 1988, p.1). 
As armas químicas foram amplamente utilizadas na guerra contra os vetores. O uso do diclorodifenil-tricloroetano (DDT), poderoso inseticida de ação residual, era utilizado no combate aos vetores da malária e de outras doenças, inclusive os flebotomíneos que transmitiam as leishmanioses cutânea e visceral (Nery-Guimarães, Bustamante, 1954, p.127). Sua aparente eficácia na saúde pública e na agricultura levou as autoridades de saúde internacionais a acreditar na possibilidade de erradicar a malária em curto prazo, mas estudos revelavam a resistência dos vetores ao inseticida (Andrade, 2016, p.71). Apesar disso, no Amazonas o DDT foi largamente utilizado nas ações de combate a endemias nas décadas de 1970 e de 1980, especialmente contra os vetores da malária em áreas de influência da Transamazônica, da BR-174 e em Balbina.

Entre 24 de maio e 22 de junho de 1988, quando acabavam de encher o reservatório da hidrelétrica, foi realizada uma excursão científica à região a fim de estudar a fauna de flebotomíneos e fazer experiências com o inseticida piretroide Deltametrina para o controle desses insetos. Era uma alternativa aos inseticidas de maior potencial tóxico, especialmente o DDT, cuja eficácia declinava à medida que se disseminava a resistência a esse composto entre insetos vetores de malária e outras doenças. A Sucam foi responsável pelas aplicações do produto, e o atendimento aos pacientes ficou a cargo do IMT. Desde 1987 eram registrados cerca de vinte casos mensais de LTA na Vila de Balbina (Inpa, 23 jan. 1988, p.1).

As investigações incriminaram a Luztomyia umbratilis como principal vetor. As moscas, com taxas elevadas de infecção, de 10\% a 30\%, eram encontradas em grande quantidade ao redor das casas e se infectavam em mamíferos que atuavam como reservatórios silvestres de Leishmania: a preguiça-real, o tamanduá e a mucura (gambá). No tocante aos flebotomíneos, os cientistas fizeram coletas tanto na base das árvores, com armadilhas de luz tipo CDC colocadas a um metro do chão e a 15 metros de altura, quanto na copa das árvores. Como a Lu. umbratilis não mostrou disposição de atacar à noite, levantaram a hipótese de que o homem era atacado no período diurno, na base das árvores, ao adentrar a mata. Porém, à noite, atraídos pela luz das casas, os insetos atacavam também crianças e mulheres no peridomicílio devido à proximidade com a floresta (Inpa, 23 jan. 1988, p.2-4).

Foram então realizadas nebulizações com Deltametrina numa faixa de floresta à margem das casas nas vilas Waimiri e Atroari, a fim de reduzir a intensidade de transmissão. Em algumas áreas não se observou redução significativa no número de flebótomos capturados após a aplicação do produto. Em outras áreas houve redução. Os cientistas sugeriram a continuidade do estudo e ações de educação em saúde, a fim de minimizar os efeitos da transmissão (Inpa, 23 jan. 1988, p.5).

Os casos provenientes dessas localidades chamavam a atenção das autoridades sanitárias e atraíam cientistas interessados na identificação das espécies de Leishmania e dos aspectos ecológicos e epidemiológicos dos surtos que irromperam na região. Contudo, foi na capital do Amazonas que a leishmaniose tegumentar explodiu como problema de saúde, forçando os governantes a reconhecer o estado de calamidade pública. 


\section{Leishmaniose em Manaus, Rio Preto da Eva e Coari}

A capital do Amazonas é um bom exemplo de como fatores ecológicos e biológicos aliados a fatores socioeconômicos transformaram a LTA em grave problema de saúde pública. Criada pela lei n.3.173, de 6 de junho de 1957, a ZFM deu origem a profundas transformações urbanas e a uma explosão demográfica na capital (Schweickardt, Martins, 2017, p.28).

A enchente de 1971 desabrigou muitas famílias no sul do Amazonas. Esse desastre, aliado à atração exercida pela ZFM e à falta de assistência à saúde no interior do estado, acentuou a migração de amazônidas para a capital. No segundo semestre irrompeu um surto de malária às margens do rio Purus, em seguida no Solimões e no rio Negro. As famílias que buscavam assistência médica juntaram-se àquelas que afluíam às ocupações periféricas de Manaus, levando consigo malária e leishmaniose. Tais doenças não tardaram a se manifestar epidemicamente nos novos bairros e ocupações da capital amazonense (Paes, Barros, Toledo, 1997, p.II.3.6).

Na segunda metade da década de 1970, as multinacionais começaram a se instalar em Manaus, e a ZFM tornou-se um vigoroso polo de atração de populações rurais do Amazonas e de estados vizinhos. A explosão demográfica (Gráfico 1) e o consequente deficit habitacional levaram as elites dirigentes e o governo a destruir extensas áreas de floresta para a construção de conjuntos habitacionais (Silva, 2011, p.521). Dessa forma, surgiram, a partir da década de 1960, os conjuntos da Cooperativa de Habitação do Amazonas (Cohab/ AM) nos bairros Raiz, Flores e Parque 10.

Gráfico 1: Crescimento demográfico de Manaus (1970-2010)

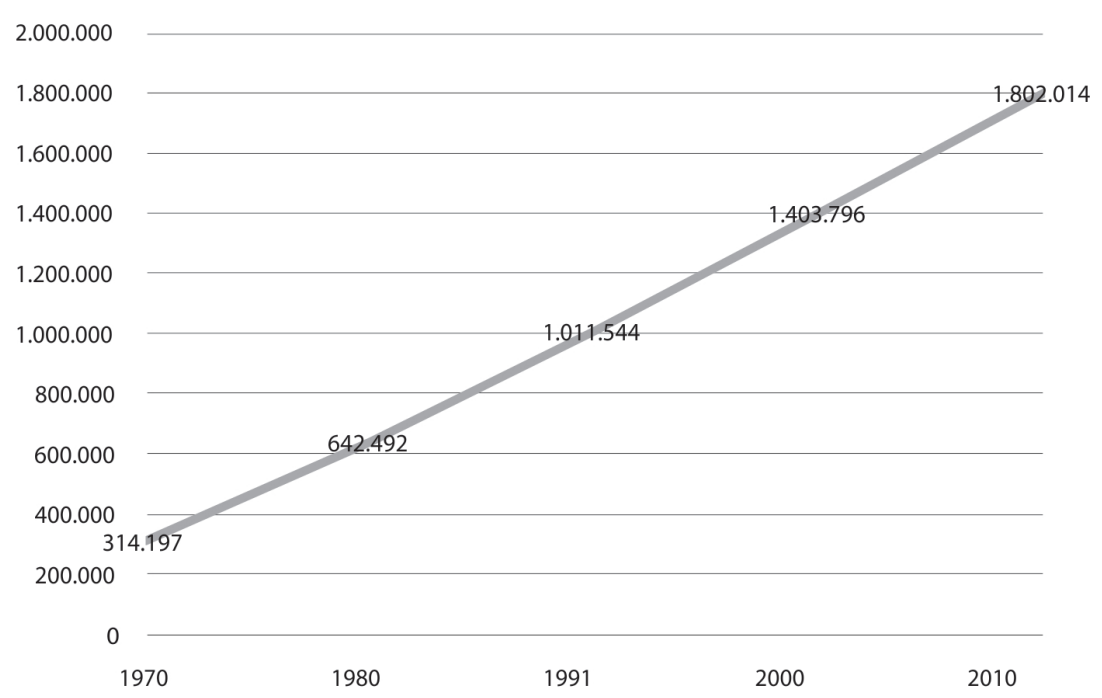

Fonte: IBGE (2010).

A leishmaniose despontava de maneira brutal na cidade de Manaus. Heitor Vieira Dourado, diretor da antiga Clínica de Moléstias Tropicais, divulgava na imprensa o primeiro grande surto no bairro Coroado, em 1971, que atingira quase cinco mil pessoas. 
Em entrevista ao Jornal do Brasil em 1972, Dourado afirmou que a febre negra de Lábrea, a leishmaniose tegumentar e a hepatite no rio Solimões eram os problemas sanitários mais sérios da Amazônia (Médico..., 24 fev. 1972).

Marcus Vinítius Guerra, médico da mesma instituição, mencionou outro grande surto durante a construção do Aeroporto Internacional Eduardo Gomes, em 1972. Lá os trabalhadores adoeceram com tamanha frequência, que essa experiência abalou o paradigma em voga de procurar apenas malária em pacientes febris, passando-se a investigar com mais atenção os parasitos (Guerra, 1 jun. 2016).

Em 1978, Marcus Luiz Barroso Barros e Marcilene Gomes Paes, médicos do Instituto de Medicina Tropical (IMT), atenderam centenas de casos de leishmaniose no pequeno ambulatório montado no bairro São José Operário, uma área de mata primária na periferia da capital desapropriada pelo governo e doada para construção de casas. Esses médicos formaram o núcleo de leishmaniose do IMT juntamente com Marcus Vinítius Guerra, Nelson Antunes de Araújo Filho e o entomologista Nelson Fé. Em meados dos anos 1980, juntou-se ao grupo o médico Jorge Augusto de Oliveira Guerra e outros médicos e estudantes. De acordo com os boletins epidemiológicos, a leishmaniose só perdia para a malária em número de casos (Barros, 12 set. 2016).

Naquele ano, além da proliferação das ocupações na periferia da capital amazonense, o governo construía novo segmento do conjunto habitacional Cidade Nova com mais de 10 mil casas, inaugurado em etapas a partir de 1981. O terreno onde o conjunto era construído fora totalmente desmatado. Devido à proximidade com a mata, à falta de serviços básicos de coleta de lixo e água e à presença abundante do vetor, houve grandes surtos (Andrade, 1998, p.35). De acordo com a imprensa local, durante o auge dessa epidemia eram atendidas cerca de trezentas pessoas diariamente (Surto..., 12 jul. 1985).

Os estudos feitos à época mostravam que a LTA acometia com frequência trabalhadores e moradores que atuavam ou residiam em áreas contíguas às florestas. A doença se manifestava, principalmente, por meio de lesões cutâneas (únicas ou múltiplas), de características rasas, circulares, com bordas bem definidas, cujo período de incubação variava de duas semanas a vários meses e, mais raramente, sob a forma mucosa (Paes, Barros, Toledo, 1997, p.II.3.5). Havia a crença popular de que o extrato de um tipo de tubérculo (Zamia ulei), conhecido como "batata de onça", curava as "feridas bravas". Em 1988, os cientistas do Inpa tentaram comprovar a eficácia dessa planta amazônica no tratamento da doença. Contudo, o estudo realizado em hamsters revelou que "diferentemente da esperada ação leishmanicida, os resultados experimentais indicaram uma atividade extremamente perigosa" (Silva et al., 1988, p.212).

O tratamento com antimoniais era doloroso e potencialmente tóxico. Atualmente, a forma pentavalente do antimoniato de meglumina (Glucantime) é a droga de primeira escolha, e as pentamidinas e a anfotericina B são utilizadas em casos que não respondem ao tratamento com os antimoniais (Rath et al., 2003, p.551-554). O IMT testava novas drogas no tratamento e realizava grande parte dos atendimentos clínicos, já o Inpa ampliava os conhecimentos sobre as espécies de interesse médico. Rui Alves Freitas, entomólogo do Inpa, participou de um dos tratamentos alternativos desenvolvidos no IMT com a droga Rifampicina ${ }^{9}$ quando contraiu em campo a leishmaniose causada pela L. (V.) guyanensis, 
porém, a resposta terapêutica da droga testada foi inferior ao tratamento com o antimonial (Freitas, 18 maio 2017). Na década de 1980, a epidemia elevou os números para mais de mil casos por ano.

No Amazonas, foram registrados 3.464 casos de leishmaniose tegumentar em 1985 e 1.641 casos no ano seguinte, voltando a crescer em 1987 para 2.528 e, em 1988, para 2.532 (Guerra et al., 2015, p.13). Mais de 50\% desses casos foram atendidos no IMT. Grande parte dos pacientes provinha da Cidade Nova, Colônia Santo Antônio e áreas adjacentes. A maioria dos casos ocorreu em ocupações irregulares denominadas "invasões" e loteamentos que se disseminavam em várias zonas da cidade: São José, Tancredo Neves, Cidade de Deus e outros. Nessas áreas, o desmatamento aliado às condições sanitárias precaríssimas, combinadas a condições biológicas propícias e ao contato com insetos vetores e hospedeiros vertebrados infectados por Leishmania, ocasionou graves surtos de LTA (Barrett, Senra, 1989, p.255).

No final da década de 1990 e início dos anos 2000, quando a urbanização estabilizou os casos naquelas áreas, os estudos realizados pelo Inpa e pelo IMT buscaram elucidar a relação entre a epidemiologia da leishmaniose, a dinâmica da vegetação e os fatores climáticos, especificamente, a pluviosidade e a densidade de flebótomos. Na região metropolitana de Manaus (Careiro da Várzea, Iranduba, Itacoatiara, Manacapuru, Novo Airão, Presidente Figueiredo e Rio Preto da Eva), que concentra a maior quantidade de casos de LTA do estado (Maciel, 2013, p.17). Verificou-se que os surtos durante o ano variavam conforme o período das chuvas. De novembro a junho, as áreas de risco eram acentuadas, enquanto de julho a outubro, período da vazante, o risco diminuía (Carvalho, 2011, p.55).

Da mesma forma, os estudos realizados a partir de 2001 no município de Rio Preto da Eva (o segundo do estado em número de casos), onde o Inpa estabeleceu uma importante parceria com o Hospital Thomé de Medeiros Raposo e a Unidade Básica de Saúde Manoel Rumão, detectaram que os fatores climáticos e sociais favoreciam o surgimento de casos, especialmente nos pacientes provenientes dos assentamentos ao longo da AM-010. Nas visitas semanais, os cientistas coletavam flebótomos e material das lesões em busca das espécies de vetores e parasitos. Investigações realizadas entre 2005 e 2012 levaram à identificação de flebótomos relacionados à infecção pela L. (V.) guyanensis, responsável por mais de $80 \%$ dos casos naquela área, e foram encontrados casos relacionados à Leishmania (V.) naiffi e à Leishmania (L.) amazonensis (Figueira et al., 2014, p.173; Naiff Jr., 2009, p.103).

Investigações similares foram feitas por cientistas da Universidade Federal do Amazonas (Ufam) em um polo de exploração de petróleo da Petrobras na microrregião do Médio Solimões, na região de Urucu, município de Coari, distante de Manaus cerca de $650 \mathrm{~km}$. Em 1986, quando a empresa anunciou a descoberta de uma grande jazida de gás natural, a construção de um gasoduto tornou-se objeto de grande polêmica devido às discussões sobre as viabilidades socioambientais e econômicas da obra. Sua finalidade era abastecer a capital do Amazonas, que já era o segundo maior polo industrial do país.

Os cientistas verificaram que as condições do bioma proporcionavam grande diversidade de espécies de Leishmania, incluindo as que causam doença no homem. Paralelamente aos estudos desenvolvidos pela Ufam, Luís Gomes, Liliane Nery, Francimeire Gomes, Rui Freitas e Antônia Franco, pesquisadores do Inpa, iniciaram em agosto de 2003 um levantamento da fauna de flebotomíneos na área de influência do gasoduto Urucu-Coari-Manaus. 
Conseguiram identificar 25 espécies pertencentes a oito subgêneros e quatro grupos, sendo a Lutzomyia umbratilis a mais abundante (Gomes et al., 2009, p.234).

Em 2006, quando foi iniciada a construção do gasoduto, os surtos ameaçavam as obras. Os operários contraíam a doença devido à exposição a flebotomíneos infectados ao entrar na mata fechada para realizar levantamentos geofísicos, diagnósticos ambientais, geotécnicos, projetos sísmicos terrestres e sondagens diversas. Em Coari, a doença foi classificada como enfermidade ocupacional, devido ao padrão de transmissão ligado ao ciclo silvestre (Alecrim et al., 2014, p.76). Com o fim das obras na região, a incidência diminuiu.

No Amazonas, a LTA tem acometido crianças, jovens, adultos e idosos de ambos os sexos, especialmente os que habitam e desenvolvem suas atividades próximos a áreas de floresta. Os grandes projetos de desenvolvimento geraram desequilíbrio ambiental e resultaram no contato homem/vetor em áreas de risco e no aparecimento de surtos. A leishmaniose impôs-se então à agenda dos serviços e instituições ligados à saúde na capital do Amazonas e passou a mobilizar um número cada vez maior de médicos, sanitaristas e cientistas como objeto de pesquisa, de assistência médica e, em medida bem menor, de medidas preventivas e educativas.

\section{Considerações finais}

Foi nos anos 1970 que a leishmaniose tegumentar americana emergiu como um grande problema de saúde na região amazônica. Esse processo aconteceu em estreita associação com mudanças econômicas e políticas que causaram profundas alterações socioambientais, urbanas e demográficas. Contribuíram significativamente para isso o fluxo migratório desencadeado pela implantação da Zona Franca de Manaus em 1967 e outros projetos de desenvolvimento no decorrer das décadas subsequentes.

Há certa similitude entre os surtos observados no início do século XX em São Paulo, durante a construção de uma estrada de ferro, e aqueles mais recentes, articulados à implantação de grandes projetos governamentais na Amazônia. Nos dois casos, as epidemias de leishmanioses cutânea e mucocutânea têm ligação com a presença de humanos nas matas e com os desmatamentos de extensas áreas florestais para grandes obras.

O intenso fluxo de migrantes, a desenfreada ocupação da periferia de Manaus, o deslocamento de trabalhadores para a construção das rodovias BR-174 e AM-010, a exploração mineral em Pitinga e a hidrelétrica de Balbina favoreceram a incidência da leishmaniose. Na capital, a população em busca de trabalho encontrou uma dura realidade, como a dos moradores da Colônia Santo Antônio narrada no início deste artigo. Privada de serviços de saneamento básico, sofreu com a deterioração de suas condições de vida, enfrentando poluição, falta de água potável e ausência de serviços públicos, inclusive os de saúde, num momento em que era afligida por surtos violentos de leishmaniose e malária.

As políticas econômicas adotadas no Brasil nos anos 1960 e 1970, baseadas no processo de industrialização, na modernização agropecuária e na urbanização, instauraram um modelo de desenvolvimento pautado pelo padrão rodovia-terra firme-subsolo, ainda hegemônico, que privilegia grandes obras, agronegócio, exploração mineral e madeireira 
predatória, escamoteando seu custo ambiental. Esse modelo tem causado mudanças rápidas nos ecossistemas, ameaçados pela apropriação de seus recursos naturais e pelo aumento das desigualdades relacionadas ao bem-estar e à saúde da população, à emergência da leishmaniose e de outras doenças parasitárias.

Além das transformações nos aspectos ambientais, envolvendo fauna, flora e recursos minerais, esse modelo modificou o modo de vida sociocultural e econômico dos ribeirinhos e das comunidades indígenas. Com a degradação de suas condições de saúde e saneamento, esses grupos tornaram-se muito mais vulneráveis a epidemias de doenças infectoparasitárias.

Os surtos repetidos e dificilmente controláveis de leishmaniose são um dos indicadores do esgotamento do modelo de desenvolvimento econômico atual. As condições precárias de vida das populações vulneráveis, cuja força de trabalho mantém em funcionamento esse modelo predatório e concentrador, têm como contrapartida um sistema de saúde sobrecarregado e respostas do poder público pouco efetivas.

Nesse contexto, a LTA emergiu como desafio médico-sanitário junto ao surgimento e à consolidação da Fundação de Medicina Tropical Heitor Vieira Dourado e do Instituto Nacional de Pesquisas da Amazônia. Nessas instituições foi observada grande sinergia entre ciência e assistência médico-terapêutica a pacientes na rede pública de saúde, porém, poucos avanços efetivos foram alcançados no tratamento, prevenção e controle da leishmaniose que aflige as populações do interior e as zonas periféricas de sua capital.

Essa contradição é evidente não apenas no Amazonas, mas em todo o Brasil. Embora se tenha produzido, nas últimas décadas, grandes avanços no entendimento de variados aspectos das leishmanioses, as ações do poder público para transformar esse conhecimento em medidas efetivas de controle e redução dos casos da endemia têm sido muito tímidas.

As significativas contribuições dos cientistas nas instituições do Amazonas ao estudo da leishmaniose permitiram avanços na produção de conhecimentos sobre esta doença, tornando-se uma força motriz importante no desafio de sua investigação e enfrentamento. Os processos e fatos relatados indicam a necessidade urgente de se planejar, debater e avaliar políticas e programas mais sustentáveis, justos e ecologicamente corretos no tocante ao desenvolvimento econômico, social e sanitário da Amazônia e do Brasil.

\section{NOTAS}

${ }^{1}$ A Zona Franca de Manaus (ZFM) foi idealizada por um grupo de parlamentares e intelectuais do Amazonas com base no modelo asiático e criada pela lei n.3.173, de 6 de junho de 1957, como porto livre. Implementada dez anos depois pelo governo militar, por meio do decreto-lei n.288, de 28 de fevereiro de 1967, estabeleceu incentivos fiscais por trinta anos para implantação de um polo industrial, comercial e agropecuário na Amazônia.

${ }^{2}$ Djalma da Cunha Batista, médico, escritor, presidente da Academia Amazonense de Letras e do Inpa, era um pesquisador híbrido, que transitava entre o mundo científico e o literário, havia estudado a salmonelose nos anos 1950 e tinha grande interesse na medicina tropical.

${ }^{3}$ Mário Augusto Pinto de Moraes, médico, primeiro diretor da Faculdade de Medicina da Universidade do Amazonas em 1965, diretor da Segunda Divisão de Pesquisas Médicas do Inpa (1957-1970), onde coordenou o primeiro projeto cujo objetivo era estudar a leishmaniose cutânea no Amazonas.

${ }^{4}$ Arthur César Ferreira Reis (1906-1993), político e historiador amazonense, ferrenho nacionalista e importante ator político no cenário amazônico. Foi o primeiro superintendente da Superintendência do 
Desenvolvimento da Amazônia (Sudam), antiga Superintendência do Plano de Valorização Econômica da Amazônia (SPVEA); diretor do Instituto Nacional de Pesquisas da Amazônia (1956-1958) e governador do estado do Amazonas de 24 de junho 1964 a 31 de janeiro de 1967.

${ }^{5}$ Félix Pifano Capdevielle (1912-2003), médico e pesquisador venezuelano; publicou mais de 250 trabalhos em medicina tropical, especialmente sobre doença de Chagas, leishmaniose tegumentar americana, malária, esquistossomose, arboviroses e outras doenças.

${ }^{6}$ Hervé Alexandre Floch (1908-1996), médico, biólogo e diretor do Instituto Pasteur da Guiana e do Instituto Pasteur de Guadalupe. Incriminou a L. tropica guyanensis como o organismo causador do pian-bois (LTA) na Guiana.

${ }^{7}$ Existe enorme dificuldade na classificação das espécies do gênero Leishmania, devido à grande semelhança morfológica entre elas. Inicialmente, suas espécies eram identificadas em função do aspecto clínico das doenças, embora os dados epidemiológicos de vetores e reservatórios sugerissem que as populações de parasitas eram extremamente heterogêneas. Baseados em critérios extrínsecos, como comportamento do parasito em cultura e em hamster, Lainson e Shaw reuniram as espécies em três complexos: Leishmania braziliensis, Leishmania mexicana e Leishmania donovani e, em 1987, com base em características clínicas e epidemiológicas, revisaram essa classificação, apoiada em aspectos biológicos, bioquímicos e moleculares dos parasitos, em dois subgêneros: Viannia e Leishmania.

${ }^{8}$ O Estudo de Impacto Ambiental (EIA) e o Relatório de Impacto Ambiental (Rima) são documentos técnicos multidisciplinares com objetivo de realizar uma avaliação ampla e completa dos impactos ambientais significativos e indicar as medidas mitigadoras correspondentes.

${ }^{9}$ Antibiótico que age inibindo a multiplicação de bactérias sensíveis a esse medicamento. Especialmente usado no tratamento da hanseníase (Mycobacterium leprae) e da tuberculose (Mycobacterium tuberculosis).

\section{REFERÊNCIAS}

ALECRIM, Priscilla H. et al.

Leishmaniose tegumentar americana associada à exposição ocupacional de trabalhadores da indústria petrolífera na Amazônia Brasileira. Scientia Amazonia, v.23, n.3, p.72-79. 2014.

ALTAMIRANO-ENCISO, Alfredo J. et al. Sobre a origem e dispersão das leishmanioses cutânea e mucosa com base em fontes históricas pré e pós-colombianas. História, Ciências, SaúdeManguinhos, v.10, n.3, p.853-882. 2003.

ANDRADE, Romulo de Paula.

A saúde em tempos de desenvolvimento: a campanha de erradicação da malária na Amazônia. História Revista, v.20, n.3, p.58-79. 2016.

ANDRADE, Simone L.

Leishmaniose tegumentar americana em área de ocupação recente na periferia da cidade de Manaus, estado do Amazonas - Brasil. Dissertação (Mestrado em Medicina Tropical) - Fundação Oswaldo Cruz, Rio de Janeiro. 1998.

ARAÚJO FILHO, Nelson A.

Leishmaniose tegumentar americana e o desmatamento da Amazônia. Acta Amazônica, v.11, n.1, p.187-189. 1981.

ARIAS, Jorge R.; FREITAS, Rui A.

Sobre os vetores de leishmaniose cutânea na Amazônia Central do Brasil: incidência de flagelados em flebótomos selváticos. Acta Amazônica, v.8, n.3, p.387-396. 1978.
BARRETT, Toby V.; SENRA, Márcia dos S. Leishmaniasis in Manaus, Brazil. Parasitology Today, v.5, n.8, p.9109. 1989.

BARROS, Marcus Luiz Barroso. [Entrevista]. Entrevistadores: Jaime L. Benchimol e Cláudio de O. Peixoto. Manaus: Instituto Leônidas e Maria Deane. 1 arquivo mp3. Entrevista concedida ao Projeto História das Leishmanioses (1903-2015): significados, enfrentamento e desafios de uma doença dos trópicos que se tornou risco global. 12 set. 2016.

BATISTA, Djalma.

O complexo da Amazônia: análise do processo de desenvolvimento. Manaus: Valer; Edua; Inpa. 2007.

BENCHIMOL, Jayme Larry; SILVA, André Felipe C. da.

Ferrovias, doenças e medicina tropical no Brasil da Primeira República. História, Ciências, Saúde Manguinhos, v.15, n.3, p.719-762. 2008.

BRASIL.

Manual de Vigilância da Leishmaniose Tegumentar Americana. Ministério da Saúde, Secretaria de Vigilância em Saúde, Departamento de Vigilância Epidemiológica. Brasília: Editora do Ministério da Saúde. 2017.

CARVALHO, Afrânio de Lima.

Casos de leishmaniose tegumentar americana na região metropolitana de Manaus e suas relações com a dinâmica da vegetação e com a variabilidade 
climática. Dissertação (Mestrado em Clima e Ambiente) - Instituto Nacional de Pesquisas da Amazônia, Manaus. 2011.

CHAGAS, Andrezza Campos et al. American Cutaneous Leishmaniasis (ACL) in a mining village - Pitinga, Amazonas, Brazil. Revista Brasileira de Epidemiologia, v.9, n.2, p.186192. 2006.

CONCEIÇÃO-SILVA, Fátima; ALVES, Carlos. A. Leishmanioses do continente americano. Rio de Janeiro: Editora Fiocruz. 2014.

FAULHABER, Priscilla.

A história dos institutos de pesquisa na Amazônia. Estudos Avançados, v.19, n.54, p.241-257. 2005.

FIGUEIRA, Luana de Paula et al.

Distribuição de casos de leishmaniose tegumentar no município de Rio Preto da Eva, Amazonas, Brasil. Revista de Patologia Tropical, v.43, n.2, p.173-181. 2014.

FONSECA, Ribamar.

A silenciosa guerra contra a leishmaniose.

Jornal do Comércio, n.22.490, p.1.

Disponível em: <http://memoria.bn.br/

DocReader/170054_01/163297>. Acesso em: 22

abr. 2018. 19 jun. 1977.

FREITAS, Rui Alves de.

[Entrevista]. Entrevistador Cláudio Peixoto. Manaus, Instituto Leonidas e Maria Deane. 1 arquivo mp3. Entrevista concedida ao Projeto História das Leishmanioses (1903-2015): significados, enfrentamento e desafios de uma doença dos trópicos que se tornou risco global. 18 maio 2017.

GOMES, Luiz Henrique Monteiro et al. Fauna de flebotomíneos (Diptera: Psychodidae: Phlebotominae) em terra firme e planície fluvial na área de influência do gasoduto CoariManaus, Amazonas, Brasil. Acta Amazônica, v.39, n.1, p.233-236. 2009.

GONÇALVES, Carlos W.P. Amazônia, Amazônias. São Paulo: Contexto. 2008.

GUERRA, Jorge Augusto de Oliveira et al. Tegumentary leishmaniasis in the state of Amazonas: what have we learned and what do we need? Revista da Sociedade Brasileira de Medicina Tropical, v.48, p.12-19. 2015.

GUERRA, Jorge Augusto de Oliveira et al. Aspectos clínicos e diagnósticos da leishmaniose tegumentar Americana em militares simultaneamente expostos à infecção na Amazônia. Revista da Sociedade Brasileira de Medicina Tropical, Uberaba, v.36, n.5, p.587-590. 2003.
GUERRA, Marcos Vinítius de Farias.

[Entrevista]. Entrevistadores: Jaime L. Benchimol e Cláudio de O. Peixoto. Manaus, Instituto Leônidas e Maria Deane. 1 arquivo mp3. Entrevista concedida ao Projeto História das Leishmanioses (1903-2015): significados, enfrentamento e desafios de uma doença dos trópicos que se tornou risco global. 1 jun. 2016.

IBGE.

Instituto Brasileiro de Geografia e Estatística. População dos municípios das capitais (população presente e residente). Disponível em: <http://seriesestatisticas.ibge.gov.br/series. aspx?vcodigo $=\mathrm{CD} 79 \& \mathrm{sv}=58 \& \mathrm{t}=$ populacao - dos municipios-das-capitais-populacao-presente-eresidente>. Acesso em: 04/08/2020. 2010.

INPA.

Instituto Nacional de Pesquisas da Amazônia. Relatório Semestral de Acompanhamento Segmento Doenças endêmicas Leishmaniose/ Doença de Chagas. Estudos de Ecologia e Controle Ambiental na Região do Reservatório da UHE Balbina. Convênio ELN/MCT/Inpa. 23 jan. 1988.

INPA.

Instituto Nacional de Pesquisas da Amazônia. Relatório Anual do Inpa. Exercício 1963. Manaus: Inpa. 1963.

JOGAS JR., Denis G.

Uma doença americana? A leishmaniose tegumentar na produção de conhecimento em medicina tropical (1909-1927). Dissertação (Mestrado em História das Ciências e Saúde) Fundação Oswaldo Cruz, Rio de Janeiro. 2014.

LAINSON, Ralph.

The Neotropical Leishmania species: a brief historical review of their discovery, ecology and taxonomy. Revista Pan-Amazônica de Saúde, v.1, n.2, p.13-32. 2010.

\section{LEISHMANIOSE...}

Leishmaniose está em fase de controle. Jornal do Comércio, n.33.654, p.4. Disponível em: <http:// memoria.bn.br/DocReader/170054_02/13140>. Acesso em: 10 abr. 2018. 14 jul. 1985.

MACIEL, Marcel G.

Distribuição Espacial e Temporal da Leishmaniose Tegumentar Americana (LTA) no estado do Amazonas no período de 2001 a 2010. Dissertação (Mestrado em Doenças Tropicais e Infecciosas). Universidade do Estado do Amazonas, Manaus. 2013.

\section{MÉDICO...}

Médico vê febre negra entre problemas sanitários mais graves da Amazônia. Jornal do Brasil, n.272, Primeiro caderno, p.15. Disponível em: <http://memoria.bn.br/docreader/ DocReader.aspx?bib=030015_09\&pagf is $=51163$ > . Acesso em: 16 abr. 2018. 24 fev. 1972 . 
NAIFF JR., Roberto Daibes.

Estudo de uma série de casos de leishmaniose tegumentar americana na população de Rio Preto da Eva. Revista de Patologia Tropical, v.38, n.2, p.103-114. 2009.

NERY-GUIMARÃES, Felipe; BUSTAMANTE, Fernando M. de.

A aplicação domiciliária de DDT como base da profilaxia das leishmanioses. Estudo de um foco de leishmaniose mucocutânea cinco anos depois da aspersão periódica com aquele inseticida. Revista Brasileira de Malariologia e Doenças Tropicais, v.6, n.1, p.127-130. 1954.

OMS.

Organização Mundial da Saúde. Control of the leishmaniases: World Health Organization technical report series. Wasghinton: WHO. 2010.

PAES, Marcilene Gomes; BARROS, Marcus L.B.; TOLEDO, Luciano M.

Considerações sobre a produção da leishmaniose tegumentar americana no Estado do Amazonas. In: Iniguez-Rojas, Luisa; Toledo, Luciano (Org.). Espaço e doença: um olhar sobre o Amazonas. Rio de Janeiro: Fiocruz. p.105-130. 1997.

PATZ, Jonathan A. et al.

Effects of environmental change on emerging parasitic diseases. International Journal for Parasitology, v.30, n.12-13, p.1395-1405. 2000.

PEIXOTO, Cláudio de O.

Leishmaniose tegumentar americana: história, políticas e redes de pesquisa no Amazonas (19702015). Dissertação (Mestrado em Condições de Vida e Situações de Saúde na Amazônia). Fundação Oswaldo Cruz, Manaus. 2017.

PESSOA, Samuel Barnsley; BARRETO, Mauro Pereira.

Leishmaniose tegumentar americana. Rio de Janeiro: Ministério da Educação e Saúde; Imprensa Nacional. 1944.

PINHEIRO, Francimeire Gomes; LUZ, Sérgio Luis. B.; FRANCO, Antônia Maria R. Infecção natural por tripanosomatídeos (Kinetoplastida: Trypanosomatidae) em Lutzomyia umbratilis (Diptera: Psychodidae) em áreas de leishmaniose tegumentar americana no Amazonas, Brasil. Acta Amazônica, v.38, n.1, p.165-172. 2008.

RATH, Susanne et al. Antimoniais empregados no tratamento da leishmaniose: estado da arte. Química Nova, v.26, n.4, p.550-555. 2003.
RODRIGUES, Renan Albuquerque.

Vidas despedaçadas: impactos socioambientais da construção da Hidrelétrica de Balbina (AM), Amazônia Central. Dissertação (Mestrado Sociedade e Cultura na Amazônia) - Universidade Federal do Amazonas, Manaus. 2013.

SCHWEICKARDT, Júlio César; MARTINS, Ludmila R.

História das políticas de saúde no Amazonas:

da Zona Franca ao SUS, 1967-1990. In:

Schweickardt, Júlio et al. (Org.). História e política pública de saúde na Amazônia. Porto Alegre: Rede Unida. p.19-42. 2017.

SERÁFICO, José; SERÁFICO, Marcelo.

A Zona Franca de Manaus e o capitalismo no Brasil. Estudos Avançados, v.19, n.54, p.99-113. 2005.

SHAW, Jeffrey Jon.

A partnership that worked: the Wellcome Trust and the Instituto Evandro Chagas and beyond. Revista Pan-Amazônica de Saúde, v.7, número especial, p.23-42. 2016.

SILVA, Evandro de A. et al.

Estudo farmacológico de Zamia ulei "batata de onça". Parte I. Atividade leishmanicida. Acta Amazonica, v.18, n.2, p.211-212. 1988.

SILVA FILHO, Eduardo Gomes da.

Projetos desenvolvimentistas na Amazônia e

a resistência dos waimiri-atroari,1964-2014.

Dissertação (Mestrado em História) - Universidade Federal do Amazonas, Manaus. 2015.

SILVA, José L. da.

Amazonas do extrativismo à industrialização.

Manaus: Valer. 2011.

SOUSA, Anastácio Q.; PEARSON, Richard.

Drought, smallpox, and emergence of Leishmania braziliensis in Northeastern Brazil. Emerging Infectious Diseases, v.15, n.6, p.916-921. 2009.

SURTO...

Surto de leishmaniose atinge área de Colônia. Jornal do Comércio, n.33.652, p.3. Disponível em: <http://memoria.bn.br/docreader/DocReader.as px?bib=170054_02\&pagfis $=13099>$. Acesso em: 15 maio 2018. 12 jul. 1985.

VALE, Everton Carlos Siviero do; FURTADO, Tancredo.

Leishmaniose tegumentar no Brasil: revisão histórica da origem, expansão e etiologia. Anais Brasileiros de Dermatologia, v.80, n.4, p.421-428. 2005.

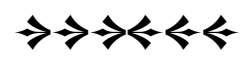

